\title{
Visão comunicacional da inovação: análise dos sentidos atribuídos à inovação na Revista da Intercom
}

\section{COMMUNICATION VISION OF INNOVATION: ANALYSIS OF THE MEANINGS} ATTRIBUTED TO INNOVATION IN INTERCOM JOURNAL

\author{
Regina Rossetti ${ }^{1}$
}

ORCID: https://orcid.org/0000-0002-3219-4570

(Universidade Municipal de São Caetano do Sul, Mestrado Profissional de Comunicação de Interesse Público-PPGCOM. São Caetano do Sul - SP, Brasil).

\section{Elias Estevão Goulart ${ }^{2}$}

ORCID: https://orcid.org/0000-0002-0687-6228

(Universidade Municipal de São Caetano do Sul, Mestrado Profissional de Comunicação de Interesse Público-PPGCOM. São Caetano do Sul - SP, Brasil).

\section{Resumo}

Este artigo investiga o uso do termo "inovação" nos trabalhos apresentados em dez anos de publicação do periódico científico Intercom - Revista Brasileira de Ciências da Comunicação. O corpus do estudo foi composto por 247 artigos publicados na revista no período de 2007 a 2017 , onde 66 artigos do total foram selecionados mediante busca do prefixo "inovaç". Com base no método de análise de conteúdo e dentre as 10 categorias elencadas a partir do material em relação à natureza da inovação, destaca-se, entre os achados da pesquisa, que o termo inovação é entendido como fenômeno tecnológico em 40,5\% das 245 citações. $\mathrm{O}$ artigo mostra ainda que a maioria dos textos discute como aspectos da inovação os seus resultados da inovação $(44,9 \%)$, embora as causas da inovação sejam abordadas por um quinto dos autores $(21,3 \%)$ e os atributos da inovação são mencionados por cerca de $20 \%$ deles.

Palavras-chave: Comunicação. Inovação. Análise de conteúdo. Intercom.

\section{Abstract}

This paper discuss the use of the term "innovation" in the articles presented in ten years of publication of the scientific journal Intercom - Brazilian Journal of Communication Sciences. The corpus of the study was composed of 247 articles published in the journal from 2007 to 2017 , where 66 articles of the total were selected by searching for the prefix "inovaç". Based on the content analysis method and among the 10 categories listed from the material in relation to the nature of the innovation, among the findings of the research, it is highlighted that the term innovation is understood as a technological phenomenon in $40.5 \%$ of the 245 citations. The article also shows that most of the texts discuss aspects of innovation as their innovation results $(44.9 \%)$, although the causes of innovation are approached by a fifth of the authors $(21.3 \%)$ and the attributes of innovation are mentioned by about $20 \%$ of them.

Keywords: Communication. Innovation. Content analysis. Intercom. 


\section{Introdução}

Historicamente, o conceito de inovação caminhou junto ao avanço tecnológico. O senso comum e, algumas vezes, até o próprio conhecimento científico, apontam que as grandes descobertas, que tornam algum produto ou processo inovador, têm como ingrediente, na maioria das vezes, a tecnologia. Essa ideia restrita de que para inovar é necessário investir em tecnologia contaminou várias áreas do conhecimento, entre elas a Comunicação e Informação, guarda-chuva que abarca a área da Comunicação Social.

No campo da ciência, a linguagem entre pares não deve ter múltiplos significados, ou seja, um conceito deve ter apenas um significado, conforme lembra Epstein:

A comunicação primária tem ainda a necessidade de utilizar uma linguagem monossêmica. A univocidade dos significados dos signos e dos semas científicos é uma condição para atender uma das condições primárias das teorias científicas: a possibilidade de sua retificação ou ratificação através do controle experimental. Como repetir um experimento ou observação, se o protocolo dos procedimentos para estas operações contém signos ambíguos ou equívocos? (EPSTEIN, 2002, p. 99).

Adelimitação do conceito de inovação é importante para indicar se sua compreensão tem sido adequada à luz das discussões em que é empregada, ou mesmo subsidiando análises e suas consequências. A abrangência do conceito e suas abordagens empregadas na área da Comunicação podem elucidar como esse atual e citado termo tem sido aplicado e, eventualmente, com significado restrito aos aspectos tecnológicos.

Inovação, geralmente, se associa à ideia do 'novo', daquilo que se apresenta e que não estava antes, como algo que surge e até pode surpreender. Há inovações que são aguardadas, ou mesmo previstas, enquanto outras trazem o inusitado. Ainda, se associa a inovação à novidade, isto é, a qualidade, caráter ou condição do que é novo. Dessa forma, o enfoque se dirige para a originalidade, ao ineditismo, o que atrai atenção e interesse. As inovações nem sempre são radicais em transformações completas, totais, implicando em estruturas, processos, métodos etc., configuradamente diferentes. Existem inovações incrementais que partem de algo já existente para, mediante processo de diferenciação, criar modificações e produzir o 'novo', que pode ser um jeito diferente de fazer, de compreender, uma nova função ou modificada em um produto, dentre outras possibilidades. Em seu livro Business Cycles, o economista austríaco Joseph Schumpeter 
(1939) diferencia os conceitos de inovação incremental e radical, sendo que a incremental se apresenta como uma melhoria sobre algo que já existe, embora sua análise tenha enfocado, principalmente, os aspectos tecnológicos.

Esta pesquisa busca investigar como o conceito de inovação se apresenta na Comunicação Social, haja vista que os pesquisadores dessa área muito empregam o termo, mas ainda pouco se debruçaram sobre o seu significado, usando a palavra como sinônimo de outras, cujos significados podem não ser tão claros como a linguagem científica preconiza. Essa lacuna de real significado de uma palavra presente em tantos segmentos da ciência, pelo menos na Comunicação Social, pode ser preenchida a partir do seu uso em textos acadêmicos da área. Portanto, a questão básica que este artigo buscou responder é: como os autores da Revista da Intercom compreendem e aplicam o sentido de 'inovação', por meio de seus textos publicados?

\section{Definições de inovação}

O termo inovação não possui um significado unívoco, ele pode ser dito em vários sentidos, assim, pode-se falar de pelo menos oito tipos de inovação: substancial, qualitativa, quantitativa, relativa, espacial, temporal, ativa e passiva. Recuperamos a seguir, de forma resumida, esses conceitos formulados e publicados em trabalho anterior (ROSSETTI, 2013).

Inovação substancial: criação e invenção. Criação e invenção são conceitos intrínsecos ao conceito de inovação, pois indicam a própria natureza do que é inovação. A criação é mais do que o simples rearranjo de elementos preexistentes, pois ela faz surgir algo novo que não existia antes, mesmo que de forma relativa. Já a invenção faz surgir o novo, isto é, algo que não existe passa a existir a partir de sua invenção. Neste sentido, inventar é diferente de descobrir. Na descoberta, a coisa já existia antes, mas ainda não era conhecida porque estava encoberta. O processo de inovação sob a categoria substancial gera aquilo que se chama de inédito, o original, o novo.

Inovação qualitativa: alteração, transformação e modificação. A inovação qualitativa produz a novidade, isto é, a qualidade do que é novo. Sob a categoria da qualidade encontram-se a alteração, a transformação e a modificação. Atos intimamente ligados ao conceito de mudança, e toda mudança é capaz de inovar no sentido de fazer surgir novos estados que não se manifestavam anteriormente. Toda alteração faz surgir novas qualidades no produto comunicacional ou no processo comunicativo. A modificação 
é a mudança nos modos, apenas é nova a maneira como são o produto da Comunicação ou o processo comunicativo, o essencial permanece o mesmo. A transformação é a mudança da forma tanto do produto comunicacional como do processo comunicativo. A transformação traz uma inovação na forma ou na estrutura do produto da Comunicação ou do processo comunicativo.

Inovação quantitativa: multiplicação. A inovação pode estar na multiplicação quantitativa do produto comunicacional. Muitos do mesmo podem ser considerados novos em relação ao único que é original. A inovação quantitativa é mais tênue e menos percebida do que a inovação qualitativa.

Inovação relativa: diversificação e diferenciação. A inovação pode estar no produto da Comunicação ou processo comunicativo com respeito a outro produto da Comunicação ou processo comunicativo. Diferenciação indica que a inovação se dá a respeito de outra coisa diferente e à alteridade em relação ao outro. Como produto da inovação relativa tem-se o diverso, o diferenciado e o diferente.

Inovação espacial: salto, tradução e transposição. A inovação pode estar fora do produto comunicacional ou do processo comunicativo como um lugar, uma situação, uma posição. A inovação acontece pela mudança no sentido de deslocamento, transição ou passagem. Pode ser um salto de um lugar a outro, uma transposição a outro lugar diferente da origem ou uma tradução.

Inovação temporal: evolução e ruptura. Quando a mudança é no sentido da geração, do aumento, tem-se a evolução, que implica continuidade e acréscimo, e desenvolvimento progressivo. A inovação pode acontecer como um processo contínuo de evolução ou aperfeiçoamento. A ruptura é a mudança por meio do corte repentino com o estado anterior e o surgimento descontínuo de um novo estado. A inovação pode surgir de forma abrupta e descontínua, como uma ruptura que faz surgir o novo.

Inovação ativa: sujeito novo ou inovado. A inovação sob a categoria da ação é tida como inovação ativa, cujo agente é o sujeito inovador. É a inovação pensada como ato em que o processo faz surgir o novo e diz respeito à ação de inovar, a ação de tornar novo, renovar. Diz respeito também ao agente inovador, isto é, o sujeito que inova e, neste sentido, a inovação está no sujeito como seu princípio. No campo da Comunicação, este sujeito inovador diz respeito aos agentes envolvidos no processo de Comunicação (como o emissor e o receptor) e diz respeito também às novas visões teóricas da Comunicação.

Inovação passiva: objeto inovado. A inovação passiva é aquela em que o objeto inovado sofreu a ação que gerou nele a inovação. É o efeito da inovação que gera um 
produto inovado. A inovação está no objeto como seu fim. É o novo que surge como resultado do processo de inovação. No campo da Comunicação, este objeto inovado pode ser um produto comunicacional.

$\mathrm{Na}$ contemporaneidade, embora mais referida como tecnológica, a inovação também acontece como fenômeno social e simbólico. Como objeto de discussão acadêmica, a inovação não apresenta uma definição unívoca, pois muitos são os entendimentos possíveis acerca deste conceito e maior ainda o número de termos correlatos. Na área da Comunicação, a inovação também é mais evidente em suas interfaces tecnológicas e nos estudos das novas mídias, entretanto, como a comunicação é um fenômeno social, a inovação se faz presente também na apropriação social que um grupo faz dessa novidade tecnológica. Mas não é somente no território tecnológico e social que podemos detectar a presença de inovações quando se investiga a comunicação. A inovação se faz presente também de forma expressiva, relacionada à educação e à ciência. Mas a inovação pode aparecer relacionada à política, linguagem, arte, cultura e nas organizações.

\section{Percurso metodológico}

Para responder à questão indicada anteriormente, foi escolhido o acervo da revista científica da Intercom - Sociedade Brasileira de Estudos Interdisciplinares, publicação com conceito Qualis A2 pela Capes (Coordenação de Aperfeiçoamento de Pessoal de Nível Superior) e cuja instituição responsável reúne cerca de 1300 pesquisadores da área de Comunicação Social, tendo sido recentemente incorporada a diversos motores de busca acadêmicos, sendo a primeira revista da área da Comunicação aprovada sistema de indexação da SciELO - Scientific Electronic Library Online. Acreditamos que o conteúdo da revista representa bem o estado da arte da área para esse fim.

Usamos a análise de conteúdo da socióloga francesa Laurence Bardin (2009) como método de análise dos artigos selecionados na amostra, identificando as categorias que pudessem contribuir para responder nossa pergunta-problema de como a inovação é conceituada pelos pesquisadores da comunicação. As categorias empregadas para o estudo de um conjunto de materiais (textos, imagens, vídeos etc.) podem ter sua origem, basicamente, de duas formas: (a) em estudos anteriores, usualmente chamados de referenciais teóricos; ou (b) no próprio conjunto de dados, a partir dos quais se busca obter categorias mais amplas ou genéricas para a classificação daqueles dados e análise de suas relações. 
Dessa forma, o emprego da análise de conteúdo pode seguir por essas duas vertentes, ou seja, realizar-se a análise dos dados a partir de categorias previamente definidas em estudos anteriores (uma determinada taxonomia); ou estabelecer-se um procedimento de categorização dos materiais coletados na pesquisa para se construir as categorias, resultantes da análise. Essa segunda forma é conhecida como Teoria Fundamentada (Grounded Theory). Na verdade, a Teoria Fundamentada (TF) se propõe a ir mais longe e gerar, a partir da coletânea de categorias recém-compiladas, uma teoria que explique o fenômeno originário daqueles materiais (BORGATTI, s.d.). A frase "grounded theory" se refere, assim, a uma teoria desenvolvida indutivamente a partir de um corpus de dados. Se corretamente executado o procedimento associado, pode-se dizer que a teoria originada se adequa perfeitamente, ao menos, àqueles dados (BORGATTI, s.d.).

Como método indutivo, a TF propõe que a informação emerja dos dados, pelo que oferece uma abordagem considerando uma maneira particular de olhar a realidade e estudá-la. De acordo com Orozco y González (2011), o objetivo da TF é gerar explicações congruentes e suficientes para a realidade, a partir da própria realidade, sem se originar no que outros teóricos tenham postulado. Ela, então, poderá abarcar dados qualitativos, quanto quantitativos (KARAM et al, 2009).

Nesse estudo, pela configuração da abordagem prevista, optou-se pela TF, uma vez que o levantamento realizado das publicações na Revista da Intercom compõe o acervo de textos, em que se busca identificar o entendimento do conceito de inovação pelos pesquisadores na área da Comunicação.

Em termos procedimentais, a atividade básica na aplicação do método da Teoria Fundamentada é a leitura (e releituras) do material, primordialmente textual, e 'descobrir' e nomear 'variáveis', chamadas de categorias, conceitos, ou até mesmo propriedades, e suas inter-relações. A capacidade de reconhecer as variáveis de interesse e suas relações é chamada de 'sensibilidade teórica' (BORGATTI, s.d.). Ela é afetada pela maturidade conceitual e experimental do pesquisador na metodologia, bem como pelo emprego de técnicas para a melhoria da sua acuracidade.

Durante as (re) leituras do material, se emprega a 'codificação aberta', que é o procedimento de identificar, nomear, categorizar e descrever o fenômeno de interesse. A TF envolve atividades intensivas de coleta e análise, como destaca Choo e Lee (2014, p. 2): "use of an intensive, open-ended, and iterative process that simultaneously involves data collection, coding (data analysis), and memo-writing (theory building)"'.

\footnotetext{
1 uso de um processo intensivo, aberto e iterativo que envolve simultaneamente a coleta de dados, codifi-
} cação (análise de dados) e memorando (construção de teoria) (Tradução nossa) 
Os códigos criados, ou palavras-chave, gerarão conceitos (progressão de uma descrição para explicar os relacionamentos e novas ocorrências). Os conceitos são abstraídos pelo observador através da análise das palavras-chave. A codificação axial é a fase seguinte do processo, onde se compila e filtra os códigos obtidos na fase anterior. Nesse momento, toma-se os conceitos escolhidos, elabora-se uma reorganização e, portanto, pode-se retirar as ideias centrais e suas relações. Aplica-se agora um procedimento de dedução e indução, ou seja, abstrai-se a codificação e se busca sua validação (KARAM et al., 2009).

Dessa forma, na fase de pré-análise identificamos 247 artigos publicados pela revista da Intercom na última década, ou seja, entre 2007 e 2017. Após reunir os trabalhos em extensão PDF em pastas separadas por ano, buscamos no texto dos artigos pelas palavras que tivessem 'inovaç' em seu prefixo. A pesquisa exploratória gerou 66 artigos nesse período.

A segunda etapa de triagem, tendo agora os 66 artigos como amostra, apontou para 245 ocorrências da palavra, sendo apenas 127 úteis, porque nem todas estavam associadas a texto comentado, como por exemplo, palavras-chave, nome de disciplina de graduação, ocorrências em citações no texto etc. Com esse recorte, os artigos passaram por leitura de dois pesquisadores para serem classificados, porque nem todas estavam associadas a texto comentado pelo respectivo autor.

Observa-se que o artigo com o título de "Narrativas webjornalísticas como elemento de inovação: casos de Al Jazeera, Folha de S. Paulo, The Guardian, The New York Times e The Washington Post”, redigido pelas autoras Raquel R. Longui e Ana Marta M. Flores (LONGHI, FLORES, 2017) foi desconsiderado nas análises por 'desbalancear' os achados, uma vez que seu texto enfoca diretamente a inovação e apresenta 85 vezes o termo, o que acarretaria uma preponderância na discussão das autoras sobre os demais pesquisadores da área, ofuscando o objetivo dessa investigação que é identificar a visão sobre a inovação pela área da Comunicação, a partir das referências dos seus pesquisadores.

O Quadro 1 mostra os dados quantitativos obtidos com o levantamento bibliográfico realizado.

Quadro 1 - Resumo da busca pela palavra “inovaç” no período.

\begin{tabular}{|l|r|r|r|r|}
\hline \multicolumn{1}{|c|}{ ANO - Vol. } & \multicolumn{1}{c|}{$\mathbf{N}^{\text {os }}$} & ARTIGOS & CITAÇÕES & \multicolumn{1}{c|}{ ÚTEIS } \\
\hline $2007-\mathrm{v} 30$ & 17 & 5 & 13 & 12 \\
\hline $2008-\mathrm{v} 31$ & 15 & 4 & 8 & 8 \\
\hline $2009-\mathrm{v} 32$ & 20 & 6 & 20 & 18 \\
\hline $2010-\mathrm{v} 33$ & 21 & 4 & 7 & 7 \\
\hline
\end{tabular}




\begin{tabular}{|r|r|r|r|r|}
\hline \multicolumn{1}{|c|}{ ANO - Vol. } & \multicolumn{1}{c|}{ Nos $^{\text {aNTIGOS }}$} & CITAÇ ÕES & \multicolumn{1}{c|}{ ÚTEIS } \\
\hline $2011-\mathrm{v} 34$ & 18 & 7 & 16 & 16 \\
\hline $2012-\mathrm{v} 35$ & 30 & 7 & 26 & 17 \\
\hline $2013-\mathrm{v} 36$ & 25 & 9 & 16 & 13 \\
\hline $2014-\mathrm{v} 37$ & 22 & 5 & 19 & 16 \\
\hline $2015-\mathrm{v} 38$ & 20 & 4 & 7 & 7 \\
\hline $2016-\mathrm{v} 39$ & 29 & 6 & 7 & 3 \\
\hline $2017-\mathrm{v} 40$ & 30 & 9 & $106^{*}$ & 10 \\
\hline Totais: & $\mathbf{2 4 7}$ & $\mathbf{6 6}$ & $\mathbf{2 4 5}$ & $\mathbf{1 2 7}$ \\
\hline
\end{tabular}

Fonte: os autores

\section{A inovação na Revista da Intercom: resultados encontrados}

O processo de categorização empregado resultou em duas macrocategorias principais, a saber, a que se denominou de Tipo I, focalizando aspectos da inovação (ver Quadro 2), e a que se denominou de Tipo II, tipificando a natureza da inovação (ver Quadro 3).

Quadro 2 - Aspectos da inovação

\begin{tabular}{|c|c|}
\hline TIPO I & OCORRÊNCIA (\%) \\
\hline Resultado & 44,9 \\
\hline Causa & 21,3 \\
\hline Atributos & 20,5 \\
\hline Condicionante & 11,8 \\
\hline Definição & 1,6 \\
\hline Total & 100,0 \\
\hline
\end{tabular}

Fonte: os autores

A categoria Resultado congrega as indicações dos resultados produzidos pela inovação, como impactos na sociedade, geração de benefícios aos consumidores, mudanças na legislação, dentre outros. Por exemplo, Ana Silvia D. L. Médola (2012, p. 195) postula que "a mudança na forma de consumir introduzida pelas inovações tecnológicas gera alterações na forma de produzir", indicando que as inovações tecnológicas introduzem mudanças no consumo, ou quando Sandra P. Montardo e Vitor R. Peters (2002, p. 354) defendem que a inovação implica no crescimento econômicoé proveniente da inovação e das melhoras no processo de produção. 
Na categoria Causa, foram incluídos os aspectos que geram a inovação e, de alguma forma, determinam sua ocorrência, como o surgimento e influência de novas tecnologias digitais, personalização da vida, demandas sociais, influências culturais etc. Por exemplo, Mattelart (2009, p. 6) diz que "o novo paradigma destaca a singularidade das culturas, como uma fonte de identidade, de significado, de dignidade e de inovação social. Fala-se, já, da interdependência e da necessidade de um diálogo de culturas”, em que a inovação é decorrente das culturas que a envolvem. Herschmann (2013, p. 286) comenta que a inovação pode ser potencializada por meio de políticas inclusivas:

Diferentemente do que se frequentemente imagina: se aplicadas políticas públicas inclusivas, de potenciais protagonistas que lançam "desafios sociais" estes jovens poderiam ser convertidos em agentes de inovação, os quais podem contribuir em algum nível para a "revitalização" de megacidades, como a do Rio.

$\mathrm{Na}$ categoria Atributos se relacionou as indicações de atributos que as inovações possuem ou criam, como a possibilidade de ser apoiada, difundida, sua constante ocorrência na atualidade, sua velocidade e valor associado, dentre outras. Como exemplo, Fioravante (2013, p. 326) sugere que a inovação possui o aspecto de consumir tempo para ser adotada mas uma simples inovação como essa levou 13 anos para ser adotada.

Outro exemplo dessa categoria pode ser encontrado em Bouzon e Oliveira (2015), quando discutem sobre a pesquisa científica e abordam a inovação como um espírito da pesquisa:

A segunda é que a avaliação qualitativa, a única que nos permite apreciar a originalidade e o espírito de inovação de uma pesquisa, não pode ser substituída (p.143).

$\mathrm{Na}$ categoria Condicionante se coletou os registros dos aspectos que devem estar presentes para a ocorrência da inovação. São os elementos que condicionam a inovação, como sua necessidade de investimento, da ausência de barreiras, da ruptura epistemológica. Cita-se, por exemplo, a referência ao saber local como uma condição promotora da inovação por Marchi (2014, p. 195): 
[...] propõe-se fomentar diferentes setores produtivos que possuem como denominador comum a capacidade de gerar inovação a partir de um saber local, agregar valor simbólico a bens e serviços, além de gerar e explorar direitos de propriedade intelectual.

Ainda, quando Targino e Gomes (2011, p. 66) mencionam que a inovação deve abarcar o todo do processo e não apenas uma de suas partes. "Porém, a inovação não pode se restringir à distribuição, e sim, enfocar um novo fazer jornalístico".

Finalmente, encontraram-se menções referentes a Definições de inovação, embora em quantidade inferior à expectativa inicial em relação a esse aspecto, onde apenas dois pesquisadores indicaram algum tipo de assertiva. Gonçales $(2013$, p. 43) postula que a inovação seria um processo determinado por variantes ambientais:

Where good ideas come from (2010) busca evidenciar uma "história natural da inovação" na qual não cabe um viés antropocêntrico: a inovação seria um processo determinado por algumas variantes presentes em muitos níveis de análise, entre ambientes microscópicos como o DNA ou macroscópicos como tecnologia humana, tangíveis como os corais do Oceano Pacífico, ou abstratos como a teoria da evolução por seleção natural.

A segunda categorização produzida nesse estudo focou na natureza da inovação, resultando em 10 categorias (Quadro 3).

Quadro 3 - Natureza da inovação

\begin{tabular}{|l|r|}
\hline \multicolumn{1}{|c|}{ TIPO II } & OCORRÊNCIA (\%) \\
\hline Tecnológica & 40,5 \\
\hline Científica & 15,5 \\
\hline Comunicacional & 11,2 \\
\hline Produto / Processo / Produção & 10,3 \\
\hline Cultural & 7,8 \\
\hline Organizacional & 6,0 \\
\hline Social & 4,3 \\
\hline Política & 2,6 \\
\hline Analítica & 0,9 \\
\hline Artística & 0,9 \\
\hline & 100,0 \\
\hline
\end{tabular}

Fonte: os autores 
A categoria Tecnológica com um alto índice de ocorrência $(40,5 \%)$ era algo esperado, pois associar comunicação à tecnologia não é novidade nos estudos de comunicação.

A vinculação entre comunicação e tecnologia é tão antiga quanto a própria pesquisa em comunicação. Lazarsfeld tratou da inovação ao empreender os primeiros estudos de audiência da imprensa e do rádio. Nesse estudo, a rádio aparece como uma inovação tecnológica que traz inovação social. "Technological innovations have, it is true, a tendency of their own to engender social change [...] radio as a stupendous technical advance whit a strongly conservative tendency in all social matters"2 (LAZARSFELD, 1940, p. 332).

Ao tratar das influências mútuas e interações entre o rádio e as forças sociais, Lazarsfeld observa que as inovações tecnológicas causam mudanças sociais, embora destaque que essas inovações por si só não podem provocar tais mudanças, que somente ocorrem quando fortemente influenciadas por forças sociais externas. Essa ideia vai de encontro à análise de Barboza e Santos baseada em Rogers:

No mercado de convergência tecnológica, há constantemente mudanças e novas necessidades de políticas, difusões, inovações e demandas, a ponto de quase sempre modificar e moldar o comportamento do consumidor diante às novas inserções mercadológicas. O processo de difusão da inovação ocorre na medida em que as comunicações são transmitidas com novas ideias para o mercado (ROGERS, 2003). Quando bem difundido e experimentado, o produto é adotado ou rejeitado refletindo em mudanças sociais e mercadológicas correntes (BARBOSA; SANTOS, 2012, p. 160).

A categoria Científica talvez represente um dos resultados da Lei $n^{\circ} 10.973$, de 2 de dezembro de 2004, denominada "Lei da Inovação", que reflete a necessidade de o país contar com dispositivos legais eficientes que contribuam para o delineamento de um cenário favorável ao desenvolvimento tecnológico e ao incentivo à inovação. A partir da constatação de que a produção de conhecimento e a inovação tecnológica geram desenvolvimento, o desafio é de se estabelecer uma cultura de inovação.

Nesse contexto, o conhecimento é elemento fundamental e a inovação passa a ser veículo de transformação do conhecimento em melhoria da qualidade de vida da sociedade. Projetos de pesquisa em que a inovação seja um dos focos podem contribuir

2 As inovações tecnológicas têm, é verdade, uma tendência de engendrar a mudança social [...] como um estupendo progresso técnico com uma tendência fortemente conservadora em todos os assuntos sociais. (tradução nossa) 
significativamente para o estabelecimento desta cultura da inovação. O governo lança chamadas de financiamento de pesquisas ligadas à Ciência, Tecnologia e Inovação, e espera que nos currículos Lattes dos pesquisadores se registrem projetos, produtos, processos, técnicas, entre outros, sob a tarja da inovação. Segundo observa Wainberg:

No campo da ciência, as controvérsias são indispensáveis para a formação, a evolução e a avaliação das teorias. Mudança e inovação são autorizadas, desde que consigam vencer as resistências. Há controvérsia quando há pelos dois interlocutores que utilizam algum tipo de linguagem para se dirigir ao outro (WAINBERG, 2010, p. 226).

Embora a ênfase seja por inovação tecnológica, a própria lei fala em cultura de inovação, em conhecimento e desenvolvimento social, ampliando as possibilidades de pesquisa sobre inovação e, principalmente, requerendo que o conceito de inovação seja definido. No campo das Ciências Sociais e Humanas, a inovação é mais evidente nas interfaces tecnológicas. Todavia, a inovação está presente também no impacto social dessas novas tecnologias, segundo Passos;

Nesse caso, maior informação sobre a natureza da ciência, sua prática e possíveis impactos pode ser mais útil quando a sociedade civil estiver provida de meios e condições de influir nas decisões públicas acerca de ciência, tecnologia e inovação e julgar o andamento e resultados de projetos de pesquisa e desenvolvimento cujos temas lhes afetem de forma direta ou indireta (PASSOS, 2010, p. 2015).

A categoria Comunicacional apresenta múltiplos aspectos: o novo receptor que passa a ser também produtor de conteúdo e as novas linguagens constantemente criadas e adaptadas aos novos meios e as novas mídias. Kischinhevsky e Benzecry apontam alguns desses aspectos que requerem a inovação:

[...] inovação dos radiodifusores em termos de linguagens e formatos, concorrência com novos atores como os serviços de streaming, precarização das atividades profissionais) e a limitada diversidade de vozes (representação de mulheres, negros, LGBT e minorias, pluralidade de fontes de informação, participação efetiva da audiência) ((KISCHINHEVSKY; BENZECRY , 2017, p. 103).

Dalmonte elenca alguns questionamentos acerca das inovações comunicacionais: 
O que há de realmente novo quando se imagina a sociedade em rede? Até que ponto o indivíduo pode participar das inovações comunicacionais ou, em que medida é assegurada a sua participação? (DALMONTE, 2007, p. 138).

As inovações comunicacionais podem estar relacionadas às diversas áreas da Comunicação, como jornalismo, internet e TV. Assim se pode falar de inovações na "fase atual da imprensa, que privilegiaria as inovações na linguagem, a apresentação gráfica, o abuso no uso das cores, o design agradável, os infográficos, as fotografias e as ilustrações" (BRAGA; AGUIAR; BERGAMASCHI, 2014, p. 118). Até mesmo os meios tradicionais buscam reinventar-se: "a grande inovação da televisão do novo milénio. Ela encontrase bem expressa nos novos produtos televisivos como os videoclips, algumas séries que fazem uso da divisão do ecrã apresentando várias acções que decorrem em simultâneo como forma de substituir a tradicional sequencialidade e linearidade da imagem televisiva" (SILVA; MUNDIM, 2015, p. 26). A internet busca inovar a TV, "apesar de representar uma inovação na forma de consumo videográfico em relação à televisão, por exemplo, o YouTube deve ser visto para além da simples dicotomia entre new media e old media usualmente colocada. (SILVA; MUNDIM, 2015, p. 236).

A categoria Processo ou Produto ou Produção indica que em relação ao significado do termo inovação, ele pode ser compreendido em dois sentidos: como verbo ou como substantivo, isto é, como ato ou como efeito desse ato. Dito de outro modo, a inovação pode dizer respeito tanto ao processo quanto ao produto.

$\mathrm{Na}$ inovação entendida como ato o que está em jogo é o processo. Esse processo de inovação é capaz de gerar algo novo. Nesse sentido, a inovação se refere ao verbo inovar, à ação de tornar novo ou renovar algo, de fazer surgir a novidade. Trata-se do processo inovador, do ato de inovar, de procedimentos que geram novidades e de processos que engendram o novo. Nesse sentido:

A inovação, enquanto processo sobressaído da introdução da noção do conhecimento nos processos produtivos, apresentada como justificação das conquistas tecnocientíficas cuja missão se corporiza na mudança económica e nos reflexos do bem-estar humano (Garcia, 2010), foi naturalizada segundo o princípio da sua capacitação totalizante e inquestionável nos excursos mediáticos. A velocidade introduzida pela tecnologia nos processos de existência humana tem promovido a ideia de "inovação" como nova dimensão substitutiva dos empregos perdidos (SILVA, 2017, p. 72). 
A inovação dita como um substantivo significa o efeito que foi resultado do ato de inovar. Nesse sentido a inovação é pesada não como processo, mas como produto. Esse ato gerou uma inovação, isto é, um produto novo. Entendida como substantivo ela é precedida de um artigo: uma inovação ou a inovação, isto é, o novo, a novidade, algo que não existe e passa a existir, a coisa nova. Nesse sentido:

Duas grandes categorias de produtos representam as inovações dentro desta tendência: produtos para consumir fora do lar (baseado no conceito on the go, e popularizado inicialmente pelas lanchonetes de fast food norte-americanas) e produtos práticos para o preparo de refeições ou já prontos para serem levados e consumidos (TRINDADE; PEREZ, 2013, p.257).

Por fim, é interessante notar quer a categoria Social apresenta um índice baixo (4.3\%) se se levar em conta que se trata da área de Comunicação Social. Isso porque, nem sempre a inovação é tecnológica ou está ligada a um produto novo ou a um processo de inovação. Ela pode dizer respeito à apropriação de algo por um determinado grupo social e a inovação social que essa apropriação trouxe, gerando um novo sujeito social. Trata-se da dimensão social da inovação. Assim, a inovação cria novas realidades sociais, conforme Pereira:

De fato, as convenções dificilmente conseguem cobrir todas as situações vividas no âmbito de um mundo social. Isso abre margem para a introdução de inovações destinadas a resolver contextos específicos. Algumas delas podem ser incorporadas ao mundo social, desde que aceitas pelos demais membros (PEREIRA, 2009, p. 227).

Quando a inovação está no campo social o que é novo pode ser a apropriação social de um processo ou de uma tecnologia. O novo pode ser aquilo que é conhecido pela primeira vez por um grupo social e, nesse sentido, pode sugerir o conhecimento de algo que era estranho e desconhecido para um determinado grupo social, mas talvez não o fosse para o restante da sociedade. Assim, socialmente, a inovação pode advir da apropriação coletiva que o grupo faz de um produto ou processo. Essa nova apropriação modifica o sujeito social e transforma sua visão e sua ação no mundo. No campo social, o sujeito novo ou inovador pode ser o agente envolvido no processo de transformação social. O sujeito inovador é o sujeito que inova e, neste sentido, a inovação está no sujeito como seu princípio. 


\section{Considerações finais}

O estudo visou investigar o panorama acerca do entendimento da comunidade acadêmica na área da Comunicação, ao menos àquela parcela presente nos discursos da Revista da Intercom, em relação ao conceito da inovação. Esse conceito está presente no ideário atual, principalmente como fator crucial para o desenvolvimento das sociedades, mencionados nas análises e discussões nas mais diversas áreas, como econômica, social, educacional, dentre outras.

Seu entendimento, extensão e aplicações, na nossa área da Comunicação, deve assim receber atenção, até para que se possa estabelecer pontes ou bases para diálogos interdisciplinares.

Em linhas gerais, havia uma expectativa de que o conceito se associasse ao desenvolvimento tecnológico, o que indubitavelmente ocorreu, sendo a inovação entendida como fenômeno tecnológico, contudo por uma parte importante das menções ao termo (40,5\%), mas não com tamanha expressividade. Os colegas da área também compreendem a inovação como de natureza científica $(15,5 \%)$, comunicacional $(11,2)$ em termos de seus processos e inter-relações, e como produto ou processo em $10,3 \%$ das citações. Alguns autores também a compreendem como associada a novos produtos ou processos (10,3\%). Claramente, entende-se que as mudanças tecnológicas implicam em novas formas comunicacionais e em toda a cadeia envolvida na Comunicação, pessoas, produtos, mensagens, meios etc.

A maioria dos textos discutiu os resultados da inovação (44,9\%), embora as causas da inovação sejam abordadas por um quinto dos autores $(21,3 \%)$ e os atributos da inovação são mencionados por cerca de $20,5 \%$ deles.

O estudo sintetiza a visão de uma parcela dos pesquisadores da área da Comunicação e oportuniza espaço para que a discussão sobre esse importante conceito se amplie e auxilie na compreensão da miríade dos novos fenômenos comunicacionais atuais.

\section{Referências}

BARBOZA, J. F. D. A.; SANTOS, M. S. T. Comunicação, economia criativa e desenvolvimento local: a experiência do 'Núcleo de Comunicação Bombando Cidadania'. Intercom - RBCC, São Paulo, v. 38, n. 2, p. 61-80, Ju1/Dez 2015. 
BARDIN, L. Análise de Conteúdo. Lisboa: Edições 70 - LDA, 2009.

BORGATTI, Steve. Introduction to Grounded Theory. Disponível em: http://www.analytictech. com/mb870/introtoGT.htm. Acesso em: 16 fev.2017.

BOUZON, A.; OLIVEIRA, I. D. L. D. As revistas científicas de Comunicação Organizacional e suas marcas epistemológicas: um estudo comparativo entre França e Brasil. Intercom - RBCC, São Paulo, v. 38, n. 1, p. 129-149, Jan/Jun 2015.

BRAGA, A.; AGUIAR, L.; BERGAMASCHI, M. O chão de fábrica da notícia: contribuições para uma economia política da práxis jornalística. Intercom - RBCC, São Paulo, v. 37, n. 1, p. 111-132, Jan/Jun 2014.

CHO, Ji Young; LEE, Eun-Hee. Reducing Confusion about Grounded Theory and Qualitative Content Analysis: Similarities and Differences. The Qualitative Report, v. 19, n. 64, p.1-20, 2014.

DALMONTE, E. F. Inovações tecnológicas, Webjornalismo e fluxos informacionais: entre novas possibilidades e velhos ideais. Intercom - RBCC, São Paulo, v. 30, n. 1, p. 129-149, Jan/Jun 2007.

EPSTEIN, Isaac. Divulgação científica: 96 verbetes. Campinas: Pontes, 2002.

FIORAVANTE, C. H. Um enfoque mais amplo para o Jornalismo Científico. Intercom - RBCC, São Paulo, v. 36, n. 2, p. 315-332, Jul/Dez 2013.

GONÇALES, D. F. Sistemas, fluxos e abstrações: a Comunicação sob o 'long zoom' de Steven Johnson. Intercom - RBCC, São Paulo, v. 36, n. 2, p. 41-60, Jul/Dez 2013.

HERSCHMANN, M. Apontamentos sobre o crescimento do Carnaval de rua no Rio de Janeiro no início do século 21. Intercom - RBCC, São Paulo, v. 36, n. 2, p. 267-289, Jul/Dez 2013.

KARAM, Karoline A.; et al. Considerações sobre usos e aplicações da Grounded Theory em administração. Faces Journal, v.8, n.2, p.107-122, Abr./Jun, 2009.

KISCHINHEVSKY, M. e BENZECRY, S. A consolidação dos estudos de rádio e mídia sonora no século XXI - Chaves conceituais e objetos de pesquisa. Intercom - RBCC, São Paulo, v. 40, n. 3, p. 91-108, Set 2017. 
LAZARSFELD, Paul F. Radio and the printed page: an introduction to the study of radio and its role in the communication of ideas. New York: 1940.

LONGHI, R. R.; FLORES, A. M. M. Narrativas webjornalísticas como elemento de inovação: casos de Al Jazeera, Folha de S.Paulo, The Guardian, The New York Times e The Washington Post. Intercom - RBCC, São Paulo, 40, n. 1, Jan. 2017. 21-40.

MARCHI, L. D. Análise do Plano da Secretaria da Economia Criativa e as transformações na relação entre Estado e cultura no Brasil. Intercom, São Paulo, v. 37, n. 1, p. 193-215, Jan/Jun 2014.

MATTELART, A. A construção social do direito à Comunicação como parte integrante dos direitos humanos. Intercom - RBCC, São Paulo, v. 32, n. 1, p. 33-50, Jan/Jun 2009.

MÉDOLA, A. S. L. D. Produção e estética dos conteúdos televisivos em ambiente de convergência: o caso da TV Unesp. Intercom - RBCC, São Paulo, v. 35, n. 2, p. 189-204, Jul/Dez 2012.

MONTARDO, S. P.; PETERS, V. R. O negócio da produção de música no século 21: estudo comparativo do Jamendo e do iTunes. Intercom - RBCC, São Paulo, v. 35, n. 2, p. 351-370, Jul/ Dez 2012.

PASSOS, M. Y. Jornalismo literário e a pirâmide: implicações discursivas na Comunicação pública da ciência. Intercom - RBCC, São Paulo, v. 33, n. 2, p. 199-219, Jul/Dez 2010.

PEREIRA, F. H. O mundo dos jornalistas: aspectos teóricos e metodológicos. Intercom - RBCC, São Paulo, v. 32, n. 2, p. 217-235, Jul/Dez 2009.

ROSSETTI, Regina. Categorias de inovação para os estudos em comunicação. Comunicação \& Inovação. São Caetano do Sul, v. 14, n.27, Jul/Dez, 2013.

OROZCO, Guillermo; GONZÁLEZ, Rodrigo. Una cartada metodológica: abordajes cualitativos en la investigación en comunicación, medios y audiencias. México: Tintable, 2011.

SCHUMPETER, Joseph A. Business Cycles: A Theoretical, Historical, and Statistical Analysis of the Capitalist Process. New York: McGraw - Hill Book Company Inc., 1939.

SILVA, S. P. D.; MUNDIM, P. S. Mediações no YouTube e o caso 'Ocupação do Complexo do Alemão': características e dinâmica de uso. Intercom - RBCC, São Paulo, v. 38, n. 1, p. 231-253, Jan/Jun 2015. 
TARGINO, M. D. G.; GOMES, A. D. Comunicação para mudança social: projeto Canal*Motoboy.

Intercom - RBCC, São Paulo, v. 34, n. 2, p. 197-217, Jul/Dez 2011.

TRINDADE, E.; PEREZ, C. Aspectos dos vínculos de sentidos do consumo alimentar em São Paulo: difusão publicitária e megatendências. Intercom - RBCC, São Paulo, v. 36, n. 2, p. 245 266, Jul/Dez 2013.

WAINBERG, J. Q. A. A polêmica no Jornalismo - a cantoria dos sabiás e dos rouxinóis da mídia.

Intercom - RBCC, São Paulo, v. 33, n. 2, p. 221-237, Jul/Dez 2010.

1 Possui Doutorado e Pós-doutorado em Filosofia pela Universidade de São Paulo, Mestrado e Graduação em Filosofia pela Pontifícia Universidade Católica de São Paulo. Atualmente é docente do Programa de Pós-Graduação em Comunicação da Universidade Municipal de São Caetano do Sul - USCS. Tem experiência na área de Comunicação com ênfase em Epistemologia, Filosofia e Teorias da Comunicação. Atua na investigação interdisciplinar entre comunicação e filosofia contemporânea, pesquisando os seguintes temas: comunicação e inovação, esfera pública, comunicação de interesse público. E-mail: regina.rossetti@prof.uscs.edu.br.

2 Formação em Engenharia Elétrica pelo Centro Universitário da FEI (1982), mestrado em Engenharia Elétrica pelo Centro Universitário da FEI (1992), doutorado em Engenharia Elétrica pela Universidade de São Paulo (1998) e pós-doutorado em Human-Computer Interface pela University of British Columbia (Canadá, 2012). Atualmente é professor titular da Universidade Municipal de São Caetano do Sul (USCS) e do Centro Universitário Fundação Santo André. Tem experiência profissional nas áreas de Engenharia, Automação e Educação, e experiência acadêmica nos cursos de Engenharia, Ciência da Computação, Sistemas de Informação e Licenciatura em Computação, atuando principalmente nos seguintes temas: Comunicação e Tecnologias Digitais, Hipermídia Adaptativa e E/M-Learning. Professor colaborador do Programas de Mestrado Profissional em Comunicação da USCS. E-mail: elias.goulart@gmail.com. 